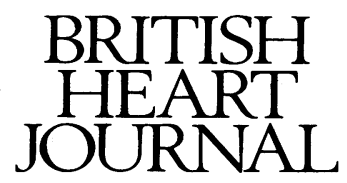

\title{
REVIEW
}

\section{Restenosis after angioplasty}

\author{
A H Gershlick, D P de Bono
}

Coronary angioplasty is now an accepted form of treatment for patients with ischaemic heart disease. In the United States 100000 procedures were performed in 1988; and in 1990 the procedure will reach parity with coronary surgery. In the United Kingdom just over 5000 procedures were performed in $1988 .^{1}$ It is clear that angioplasty is here to stay and that the indications, particularly in the United Kingdom, will expand. More operators will undertake multivessel, multilesion dilatations, though the results of various comparative trials such as the Coronary Artery Bypass Revascularisation Investigation (CABRI), Randomised Intervention Treatment of Angina (RITA), Bypass Angioplasty Revascularisation Investigation (BARI), and Emory Angioplasty Surgery Trial (EAST) may influence patient selection for percutaneous transluminal coronary angioplasty. The major limitation of this procedure is the high incidence of restenosis. Despite increased understanding of the pathophysiology of restenosis over the past ten years we are still unable to influence significantly the rate of this complication. The incidence of restenosis varies between $17 \%$ and $40 \% .^{2-6}$ The variation may be the consequence of whether there has been complete angiographic follow up as well as the way that restenosis is defined.

\section{Pathophysiology}

Balloon angioplasty causes longitudinal and circumferential splits in the vessel wall with disruption of the endothelium, intima, and media. ${ }^{78}$ Healing involves endothelial regrowth and stabilisation of the intimal and medial injury. In general, superficial endothelial injury leads to local platelet and leucocyte adhesion, but most of the platelets do not undergo a release reaction. In these circumstances re-endothelialisation is rapid and there is no subintimal proliferative response. The response to deep endothelial injury, which by definition occurs in successful angioplasty, is more complex, however. Platelet activation may be initiated by contact with deep intimal or medial collagen and contact with microfibrils and basement membrane contained within the vessel wall. Coagulation factors may be released from damaged cells, and intramural thrombus formation is probably common. The rate and adequacy of human endothelial regrowth have not been studied, but may be slow and incomplete. Part of the repair process involves the proliferation and migration of medial smooth muscle cells.

Restenosis after angioplasty is most commonly due to an excessive local proliferation of these smooth muscle cells-fibromuscular intimal hyperplasia. This has been shown both at necropsy ${ }^{9}$ and more recently in vivo by means of atherectomy devices. ${ }^{1011}$ Because activated platelets release platelet derived growth factor, which has been shown to cause migration and to influence proliferation of smooth muscle cells in vitro, it is tempting to link this proliferation with platelet activation and release at the time of the original injury, or with the continuing effects of platelet activation in the presence of a leaky endothelium. Any such theory has to take into account, firstly the relatively slow time course of restenosis and, secondly the failure of platelet inhibitory treatments to influence it in any way. There have been several clinical trials of aspirin, fish oils, and other substances known to affect platelet function. Trials of aspirin in the prevention of restenosis have been unsuccessful, irrespective of the dosage used. ${ }^{12-15}$ In one animal model of intimal hyperplasia aspirin actually enhanced proliferation, possibly by blocking prostacyclin production. ${ }^{16}$

Aspirin may be ineffective because it inhibits the wrong pathway in platelets, because the process of proliferation, once started, is self perpetuating, or less likely because platelet activation really has nothing to do with restenosis. The cyclo-oxygenase pathway that is blocked by aspirin is not required, for example, for the adhesion and activation of platelets by fibrillar collagen, thrombin, or platelet activating factor, all of which are likely to be exposed after angioplasty damage. Indeed it has been shown that platelets can adhere and be activated by collagen in the presence of aspirin. Much more potent platelet anti-aggregants are now available, including monoclonal antibodies to the glycoprotein IIb/IIIa integrin complex and von Willebrand 
factor, and snake venom peptides containing the specific platelet adhesion sequence. The problem is that they have greater effects than aspirin on haemostasis and their long term use is unlikely to be practicable. Additionally, von Willebrand factor and the glycoprotein involved in it causing platelet adherence (glycoprotein Ib) may be important only at high shear stress, a state unlikely to be present after successful angioplasty.

An initial proliferative response, set off by injury, with or without a contribution from platelets, might become self perpetuating. In vitro work suggests that only certain smooth muscle cell types proliferate and migrate ${ }^{17}$ and also that under certain circumstances smooth muscle cells (modified mesenchymal type) may themselves secrete active growth factors, thus producing a "positive feedback" effect. ${ }^{18}$ This has not been shown, however, for all types of proliferating smooth muscle cells. Alternatively, the initial proliferative stimulus may activate clones of smooth muscle with a greater proliferative capacity and less sensitivity to the usual controls (as shown by the Benditts' work on clonality in atheromatous plaques ${ }^{19}$ ). The ability to retrieve proliferating smooth muscle from the vessel during coronary atherectomy will enable both hypotheses to be tested. If it can be shown that the initial trigger is required for a short time only and that the smooth muscle cell response becomes self perpetuating or independent thereafter then a case could be made for short term, high intensity treatment to prevent an excessive platelet/thrombotic response, ${ }^{20}$ followed by longer term treatment aimed more directly at controlling smooth muscle proliferation. A recently completed study undertaken at the London Chest Hospital showed that prostacyclin given as a $36 \mathrm{~h}$ intravenous infusion in doses that can be tolerated did not prevent restenosis. $^{21}$

In vitro studies on smooth muscle proliferation emphasised the importance both of extracellular matrix and of families of growth factors whose peptide sequences have been determined but whose biological significance often remains unclear. One family of growth factors has a strong affinity for heparin; and the antiproliferative effect of heparin in some animal systems may be due to this rather than any effect on coagulation. ${ }^{22}{ }^{23}$ Cells that are moving into a proliferative phase often express the products of a series of genes called proto-oncogenes. A well known smooth muscle proto-oncoene called mas has recently been shown to control the expression of a receptor for angiotensin II. This may, or may not, have something to do with the empirical observation that angiotensin converting enzyme inhibitors can suppress vascular smooth muscle proliferation, and protooncogenes are currently being assessed for their ability to influence restenosis. Familiar drugs sometimes work in unfamiliar ways, and we are shortly likely to have more drugs available that have been specifically targeted against smooth muscle proliferation. We have been through the phase of attempting to do something about the platelets and have so far failed. This does not necessarily mean that blood factors are not involved or importantbut we do not yet have readily available agents that can fundamentally modify the blood vessel wall interaction and retain an acceptable margin of therapeutic safety. Two major assets in the assessment of new drugs and other anti-restenosis strategies would be good animal models for restenosis and a much clearer and more logical approach to the measurement of human restenosis.

\section{Definitions of restenosis}

The patient and the referring physician, are primarily interested in the relief of symptoms and preventing their recurrence. Symptoms are too variable a phenomenon to allow scientific study of quantitation of restenosis or evaluation of measures to prevent it. In clinical trials there is no substitute for follow up angiography of all patients, something that has been lacking in many large follow up studies, particularly in the United States. There are several definitions of restenosis but they essentially fall into two groups: those based on relative measurements and those based on absolute measurements. Examples of relative measurements include "presence of a $50 \%$ diameter stenosis on follow up in a patient with less than a $50 \%$ stenosis immediately post angioplasty" and "a $30 \%$ increase in $\%$ diameter stenosis from the immediate post angioplasty estimate". Holmes and colleagues compared four different "relative measurement" definitions of restenosis and found that the most sensitive was "loss of $50 \%$ of the gain in diameter at PTCA". 3 The major problem with relative measurements is that they assume that the diameter of a reference segment of the coronary tree will remain constant, and we now know that this assumption is invalid.

Serruys and his colleagues measured both stenosis and reference segment diameters immediately after angioplasty and at follow up (using catheter tip size as a further internal reference marker) and found a significant reduction in reference segment diameter in patients with restenosis. ${ }^{24}$ There is a straightforward biological explanation for this: we now know that the arterial diameter is actively modulated by endothelial shear stress, probably working through endothelium derived relaxing factor (nitric oxide); a stenosis will reduce runoff and diminish flow velocity and hence shear stress in the segment proximal to it, with consequent involution of the vessel. If we use another vessel rather than a proximal segment as the reference point, the converse will apply, with increased collateral circulation perhaps increasing the reference segment diameter. To take an extreme example, suppose we start with a $1 \mathrm{~mm}$ diameter stenosis in a $3 \mathrm{~mm}$ vessel and dilate it to $2 \mathrm{~mm}$. At follow up the treated segment has reverted to a diameter of $1 \mathrm{~mm}$, but the reference segment has involuted to a diameter of $1.5 \mathrm{~mm}$. In relative terms there is no restenosis, but obviously the procedure was a biological 
failure. The Rotterdam group have suggested that the criterion for restenosis should be a decrease in stenosis diameter which is equal to or more than twice the standard deviation for the variability in making repeated measurements of vessel diameter. For the technique they use this is $0.72 \mathrm{~mm}$. The use of twice the standard deviation is a long established scientific convention; it is perhaps unfortunate that the figure of $0.72 \mathrm{~mm}$ has sometimes been quoted out of context and therefore seems arbitrary whereas it is merely a statistical measurement, derived from the Rotterdam group's own data, that takes account of the change that could be due to chance when a lesion is observed on two occasions. Application of such a figure to individual lesions measured by different techniques or in different patient groups may be inappropriate. In the study recently completed at the London Chest Hospital the standard deviation of the measurement of video densitometry was $0.315 \mathrm{~mm}(0.63 \mathrm{~mm}=2 \mathrm{SD}) .^{21}$

The other problem with measuring absolute change and its standard deviation is that it does not take account of what would have happened if there had been no angioplasty-this information can only be obtained by some reference to the native, non-angioplastied coronary circulation. It may be true that overall the trend is for the reference "normal" diameter lumen to fall with time, however, the individual will vary and indeed the diameter of a non-angioplastied vessel could actually increase in some individuals. Nobuyoski et al have combined the apparent benefits of using absolute values with the sensitivity of the "loss of $50 \%$ of the gain" definition. ${ }^{25}$ This is probably a good compromise, with restenosis being defined as "loss of $50 \%$ of absolute gain in $\mathrm{mm}$ ".

As newer techniques appear the precision of measurement will improve and the criteria of restenosis will seem to get stricter. This does not matter if all we are interested in is the scientific comparison of two groups of patients in a controlled trial. In this case, we should avoid arbitrary definitions of restenosis and use absolute changes in stenosis diameter as continuous variables (any apparent advantage in using stenosis area rather than mean diameter is probably illusory). Whichever definition is used for restenosis it needs to be clearly stated and justified in any published data.

\section{Conclusion}

It is clear that restenosis is still a major problem after percutaneous transluminal coronary angioplasty. The data of Serruys and Nobuyoski indicate that the restenosis rate peaks within the first six months and is at least $25 \%{ }^{22}$ and may be $49 \% .{ }^{23}$ Until there are drugs that significantly inhibit adhesion of platelets to damaged vessel walls or until there is some way of making the damaged vessel wall unattractive to platelets, it may be more useful to turn our attention to preventing the consequence of the release of growth factors by platelets and white cells-namely smooth muscle cell prolifer- ation. Drugs are currently being evaluated that may limit the response of the smooth muscle cells. Only when the restenosis rate is reduced will percutaneous transluminal coronary angioplasty have fulfilled its true potential. To allow this we need clear definitions of restenosis applied to well constructed properly controlled clinical trials with high angiographic follow up.

1 Hubner PJB. Cardiac interventional procedures in the United Kingdom during 1988. Br Heart J 1990;64:36-7. Kaltenbach M, Kober G, Scherer D, Vallbracht C. Recurrence rate after successful coronary angioplasty. Eur Heart $J 1985 ; 6: 276-81$

3 Holmes DR, Vliestratra RE, Smith HC, et al. Restenosis after percutaneous transluminal coronary angioplasty (PTCA): a report from the PTCA Registry of the National Heart, Lung and Blood Institute. Am J Cardiol 1984, 53:77C-81C.

4 Mabin TA, Holmes DR, Smith HC, et al. Follow-up clinica results in patients undergoing percutaneous transluminal coronary angioplasty. Circulation 1985;71:754-60.

5 Ernst SMPG, Van der Feltz TA, Bal ET, et al. Long term angiographic follow up, cardiac events, and survival in patients undergoing percutaneous transluminal coronary patients undergoing percu 1987;57:220-5.

6 McBridge W, Lange RA, Hillis LD. Restenosis after successful coronary angioplasty. $N$ Engl J Med 1988; 318:1734-7.

7 Block PC, Myler R, Stertzer S, Fallon JT. Morphology after transluminal angioplasty in human beings. $N$ Engl J Med 1981;305:382-5.

8 Mizuno K, Kurita A, Imazeki N. Pathological findings after percutaneous transluminal coronary angioplasty. $B$ Heart $J$ 1984;52:588-90.

9 Austin GE, Ratcliff NB, Hollman J, Tabei S, Phillips DF Intimal proliferation of smooth muscle cells as an explanation for recurrent coronary artery stenosis after percutaneous transluminal coronary angioplasty $\mathrm{J} \mathrm{Am} \mathrm{Coll} \mathrm{Cardio}$ 1985;6:369-75.

10 Waller BF, Pinkerton CA, Kereiakes D, Luther S, Pinto RP Morphologic analysis of 506 coronary atherectomy specimens from 107 patients: histologically similar findspecimens from 107 patients: histologically similar findings of restenosis following primary balloon angioplasty versus primary
1990;15:197A.

11 Johnson D, Hinohara T. Simpson JB. Pathology of coronary atherectomy [Abstract]. J Am Coll Cardiol 1990;15:197A

12 Val PG, Bourassa MG, David PR, et al. Restenosis after successful percutaneous transluminal coronary angioplasty. The Montreal H

13 Leimgruber PP, Roubin GS, Hollman J, et al. Restenosis after successful coronary angioplasty in patients with single vessel disease. Circulation 1986;73:710-77.

14 Mufson $L$ Black A, Roubin $G$, et al. A randomised trial of aspirin in PTCA: effect of high vs. low dose aspirin on mairin complications and restenosis [Abstract]. J Am Coll major complications and

15 Schwartz L, Bourassa MG, Lesperance L, et al. Aspirin and dipyridamole in the prevention of restenosis after percutaneous transluminal
Med $1988 ; 318: 1714-9$.

16 Murday AJ, Gershlick AH, Syndercombe-Court YD, Lewis CT, Mills PG. Intimal thickening in autogenous vein grafts in rabbits: influence of aspirin and dipyridamole. Thorax 1984;39:457-61.

17 Ohara $T$, Nanto S, Asada S. Ultra-structural study of proliferating and migrating smooth muscle cells at the site
of PTCA as an explanation for restenosis [Abstract]. Circulation 1988;78 (suppl II):II-290.

18 Wilcox JN, Smith KM, Williams SM, Gordon D. Plateletderived growth factor $m$ RNA detection in human atherosclerotic plaques by in situ hybridization. J Clin Invest erosclerotic plaques

19 Benditt EP, Benditt JM. Evidence for a monoclonal origin of human atherosclerotic plaques. Proc Natl Acad Sci USA human atheroscler.

20 Heras M, Chesebro JH, Penny WJ, Balley KR, Badimon L, Fuster V. Effects of thrombin inhibition on the development of acute platelet-thrombus deposition during angioplasty in pigs. Heparin versus Lirudin, a specific thrombin inhibitor. Circulation 1989;79:657-65.

21 Gershlick AH, Timmis AD, Rothman M, Layton CL, Balcon R. Post angioplasty prostacyclin infusion does not reduce the incidence of restenosis [Abstract]. Presented at the American Heart Association, November 1990.

22 Clowes AW, Clowes MM. Kinetics of cellular proliferation after arterial injury iv heparin inhibits rat smooth muscle after arterial injury iv heparin inhibits rat smooth mus

23 Guyton JR, Rosenberg RD, Clowes AW, et al. Inhibition of rat arterial smooth muscle cell proliferation by heparin. In rat arterial smooth muscle cell proliferation by heparin. In vivo studies with anticoagulant
heparin. Circ Res 1980;46:625-34.

24 Serruys PW, Luijten HE, Beatt $\mathrm{KJ}$, et al. Incidence of restenosis after successful coronary angioplasty: a timerelated phenomenon. Circulation 1988;77:361-7

25 Nobuyoski M, Kimura $\mathrm{T}$, Nosaka $\mathrm{H}$, et al. Restenosis after successful percutaneous transluminal coronary angioplasty. Serial angiographic follow-up of 229 patients. $J \mathrm{Am}$ Coll Cardiol 1988;12:616-23. 